\title{
Torque Ripple Minimizing of Uniform Slot Machines with Delta Rotor via Subdomain Analysis
}

\author{
Minhyeok Lee, Yunkyung Hwang and Kwanghee Nam *
}

check for updates

Citation: Lee, M.; Hwang, Y.; Nam, K. Torque Ripple Minimizing of Uniform Slot Machines with Delta Rotor via Subdomain Analysis. Energies 2021, 14, 7390. https:// doi.org/10.3390/en14217390

Academic Editors: Damir Žarko and Ayman EL-Refaie

Received: 5 September 2021

Accepted: 4 November 2021

Published: 5 November 2021

Publisher's Note: MDPI stays neutral with regard to jurisdictional claims in published maps and institutional affiliations.

Copyright: (c) 2021 by the authors. Licensee MDPI, Basel, Switzerland. This article is an open access article distributed under the terms and conditions of the Creative Commons Attribution (CC BY) license (https:// creativecommons.org/licenses/by/ $4.0 /)$.
Department of Electrical Engineering, Pohang University of Science and Technology, 77 Cheongam-ro, Nam-gu, Pohang 37673, Gyeongbuk, Korea; leemh2014@postech.ac.kr (M.L.); yunkyung02@postech.ac.kr (Y.H.)

* Correspondence: kwnam@postech.ac.kr

\begin{abstract}
Since the slot opening is large in the uniform slot machine, the torque ripple generated by overlapping or misaligning with the rotor cavity is remarkably large in the case of interior permanent magnet (IPM) machine. In this work, it is observed that the magnitude of torque ripple depends strongly on the phase difference between air-gap field harmonics: The ripple is minimized when the two dominant harmonic components cancel each other. Based on this fact, a condition is developed to minimize torque ripple by adjusting the $q$-flux channel width and $d$-flux barrier width. The torque ripple minimizing solution is found from a level chart made by subdomain time-stepping analysis. Finite element analysis (FEA) also gives a very similar minimizing solution. A prototype machine is manufactured, and its performances are validated through experiments.
\end{abstract}

Keywords: air-gap field calculation; cavity design; delta-type rotor; open-slot; subdomain analysis; torque ripple

\section{Introduction}

Electric vehicle (EV) machines are often classified as machines of high current-low voltage. To accommodate high current, hairpin coils are widely used [1]. However, hairpin coils require so many welding points [2]. Since the copper welding in the dense area is complicated, it costs expensive automated welding equipment. As an alternative, open-slot structures are gradually adopted in the stator design for easy coil insertion from the inner air-gap side. In such a machine, preformed coils are used, so that the welding points are minimized [3].

Among various interior permanent magnet (IPM) rotors, delta types are used widely in the EV machine, since they yield high torque density and allow wide constant powerspeed range [4-7]. However, this type requires a lot of effort to minimize torque ripple due to various cavities and bridges. Torque ripple is mainly originated from non-sinusoidal PM field distribution and non-uniform reluctance of the iron core. As the rotor rotates, the reluctance fluctuates and the air-gap fields become asymmetric, resulting in cogging torque and and torque ripple [8].

The flux barrier and PM cavity must be designed to minimize the flux leakage while reducing the air-gap field harmonics. Another design consideration is to reduce torque ripple. In [9], multi-barrier cores were studied extensively, while considering torque, efficiency, back electromotive force (EMF) and iron loss. Small holes were added on the front edge sides of PM to reduce the torque ripple [10]. Hwang et al. [11] reduced torque ripple by placing notches on the rotor surface. Rectangular and elliptical notches were applied asymmetrically to the PM ends in the ' $\mathrm{I}$ '-type rotor in [12]. In an effort to increase reluctance torque while reducing the ripple, extra long barriers were put asymmetrically on the surface of ' $\mathrm{V}$ '-type rotor [13].

The overlap and separation of slot openings and rotor cavities are major sources of cogging torque and torque ripple [14]. With the use of hair pin coils, the slot opening can be made arbitrarily small, since the coils are inserted from a stack end. In [15], the slot opening 
width has been modulated to reduce torque ripple to $2 \sim 8 \%$. A fractional slot stator with an IPM rotor makes it easy to achieve low torque ripple because the least common multiple (LCM) of number of slot and pole are high $[16,17]$. However, its relatively small reluctance torque and subharmonic issue make it unsuitable for EV traction.

Skewing is a simple and traditional torque ripple reduction method applicable to all machine types. Skewing mitigates torque ripple, changes vibration mode and magnitude, but weakens torque density. As a result, noise and vibration are attenuated [18]. Multi-step skewing is mostly used in the PM machine. If the PM arrangements are not symmetrical in the axial direction, unbalanced force is created along the axis, thereby torsional vibration mode takes place in the motor housing [19]. The symmetrical PM skew in the axial direction was proposed to eliminate the unbalanced axial electromagnetic forces [20]. An alternative skewing method was attempted by carving wedge-shaped grooves asymmetrically on the tooth surface [21].

Analytic optimization is essential before the detailed design by FEA. In [22], both slotless PM model and conformal mapping were applied to predict the performance of surface permanent magnet (SPM) machine. Using the analytic results, particle swarm optimization (PSO) was introduced to find a good compromise between efficiency and torque density. On the other hand, the magnetic equivalent circuit (MEC) and the conformal mapping was used to predict the cogging torque $[23,24]$. Though it predicted air-gap fields accurately, a large error was observed in the cogging torque when the core was saturated.

The subdomain analysis was also utilized extensively to predict the performances of SPM machine [25,26]. Shin et al. [27] obtained optimal slot opening and pole arc ratio to minimize the cogging torque of SPM machine by using the subdomain analysis. The torque ripple change due to the flux modulation slot of SPM machine was also well predicted [28]. However, the cores are assumed to be infinitely permeable in most subdomain analysis. In order to take care of core saturation, additional domains have to be set with a finite permeability. Then the equations turn out to be the r-edge boundary problem $[29,30]$. In [31], both FEA and subdomain analysis were used in optimizing an IPM machine, where the PM field was obtained from FEA and the armature reaction field was obtained by a simplified subdomain method.

For low cost machine design, a uniform (open) slot stator with a delta PM rotor is a practically attractive option for easy coil insertion. In this study, we investigate a torque ripple reduction method for a uniform slot IPM machine with a delta PM arrangement. Based on the Maxwell stress tensor, we focused on the phase difference between the radial and circumferential air-gap fields, adjusting the channel width of the $q$-axis flux path and the cavity width of the $d$-axis. A design criterion is obtained by eliciting cancellation between the dominant high order components. The optimal solution is found using the subdomain analysis and FEA.

This paper is organized as follows: In Section 2, a reference design and its subdomain model are illustrated and the necessary equations for subdomain analysis are presented with the torque equation. It is discussed in Section 3 that the torque ripple is directly related to the phase profiles of high order torque components in the time-stepping analysis. An index is developed to reduce the torque ripple. Level charts are made over the various combinations of design parameters in Section 4. The validity is also verified through FEA. In Section 5, a prototype machine is manufactured, and its performances are validated in experiment.

\section{Subdomain Analysis for Delta IPM Rotor}

The target power and torque of machine are $15 \mathrm{~kW}$ and $90 \mathrm{Nm}$. The maximum operating speed is $7000 \mathrm{rpm}$. The cross-sectional area of magnet is fixed as $3.5 \times 12 \mathrm{~mm}^{2}$ due to the limitation of PM weight and price. The main parameters of the designed machine are listed in Table 1. 
Table 1. Parameters of Delta-IPM with Uniform Slot Machine.

\begin{tabular}{cccc}
\hline Parameter & Values & Parameter & Values \\
\hline Outer slot radius, $r_{s o}$ & $91 \mathrm{~mm}$ & Inner slot radius, $r_{t}$ & $58.8 \mathrm{~mm}$ \\
Air-gap radius, $r_{a}$ & $58 \mathrm{~mm}$ & Outer barrier radius, $r_{o b}$ & $56 \mathrm{~mm}$ \\
Radial PM radius, $r_{r m}$ & $58.5 \mathrm{~mm}$ & Circum. PM radius, $r_{\theta m}$ & $44.5 \mathrm{~mm}$ \\
Inner barrier radius, $r_{i b}$ & $38.5 \mathrm{~mm}$ & Stack length, $L_{z}$ & $120 \mathrm{~mm}$ \\
Outer stator radius & $100 \mathrm{~mm}$ & Inner rotor radius & $27 \mathrm{~mm}$ \\
Pole pair, $p$ & 4 & Slot number, $Q_{s}$ & 48 \\
Current density, $J_{i}$ & $7.5 \mathrm{~A}_{\mathrm{rms}} / \mathrm{mm}^{2}$ & Base speed, $\omega_{r}$ & $167.5 \mathrm{rad} / \mathrm{s}$ \\
Target torque & $90 \mathrm{Nm}$ & Target max.power & $15 \mathrm{~kW}$ \\
\hline
\end{tabular}

\subsection{Equivalent Model for Subdomain Analysis}

Differently from SPM rotor, the IPM rotor has multiple cavities to minimize the PM field leakage. The cavities for PM differentiate the rotor reluctance depending on the axis, so that $L_{d}$ and $L_{q}$ are different. However, the delta-type rotor requires relatively many bridges as shown in Figure 1a. The practical design is modified schematically as shown in Figure $1 \mathrm{~b}$ for subdomain analysis. Note that the frontal PM to the air-gap is converted a one in the groove with a steel cap on the top. The angles of V-shaped PMs are also modified, so that they are aligned to the radial direction. Finally, the cavities in the shaft side are enlarged along the circumferential direction.

In fact, the narrow bridges around cavity are neglected in the analysis since they are always saturated by the PMs. Further, if a bridge is assumed with infinite permeability, enormous flux is supposed to leak out through it. Therefore, all the narrow bridges are removed in this subdomain model. On the other hand, we assume for simplicity that the steel cores are infinitely permeable.

In practice, small amount of PM flux leaks through the bridge. This PM flux loss is considered by lowering the remnant flux density of PM such that [32]:

$$
\begin{aligned}
B_{r m}^{S u b} & =B_{m} \frac{w_{r m}-2 w_{b o o} \frac{2(\mathrm{~T})}{B_{m}}-2 w_{b o i} \frac{2(\mathrm{~T})}{B_{m}}}{r_{o b} \phi_{r m}}, \\
B_{\theta m}^{S u b} & =B_{m} \frac{w_{\theta m}-w_{b o o} \frac{2(\mathrm{~T})}{B_{m}}-w_{b i i} \frac{2(\mathrm{~T})}{B_{m}}}{r_{a}-r_{\theta m}},
\end{aligned}
$$

where $B_{m}$ is the remnant flux density of a real PM. $w_{r m}$ is the outer magnet width, $w_{\theta m}$ is the $V$-shape magnet width, and $w_{b o o}, w_{b o i}$, and $w_{b i i}$ are the bridge width. 


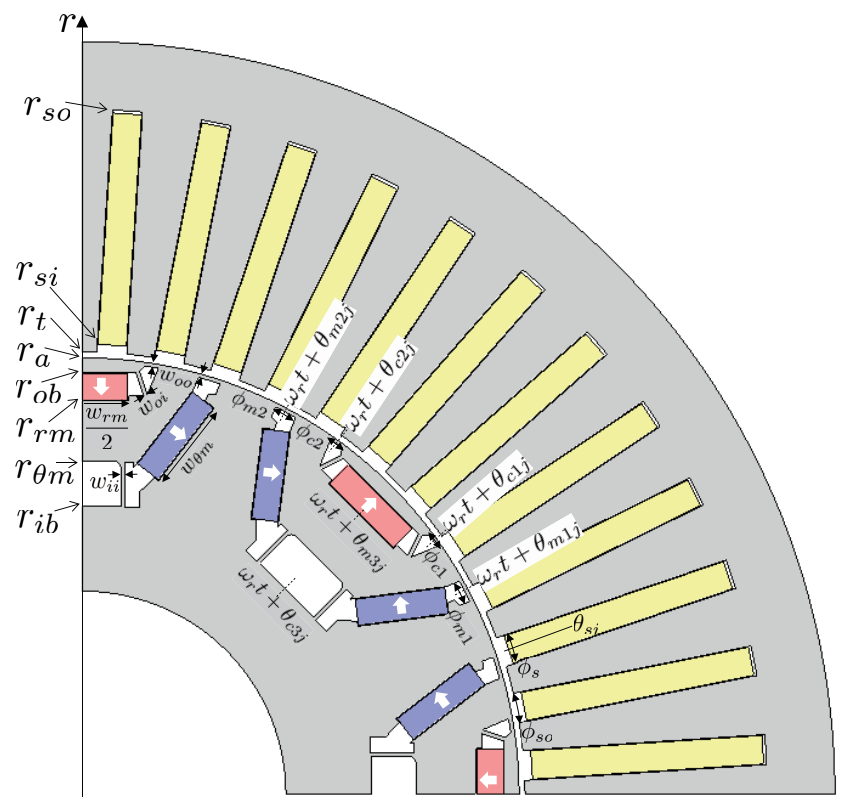

(a)

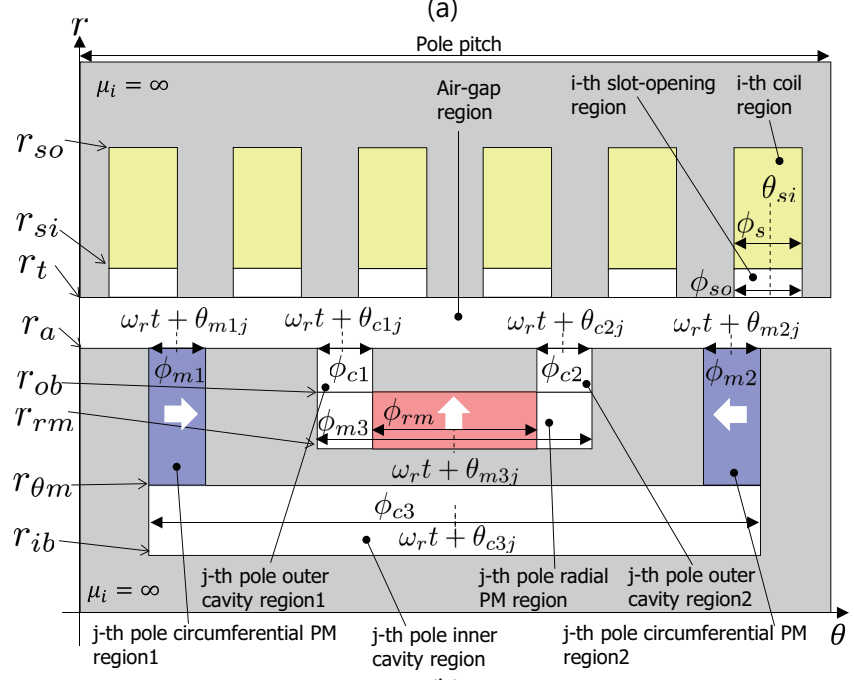

(b)

Figure 1. Machine configurations: (a) delta rotor with uniform slot stator and (b) equivalent model for subdomain analysis.

\subsection{General Solutions and Boundary Conditions}

A delta-IPM with $p$ pole pair and $Q_{s}$ stator slots is considered with the following assumptions: the coil end turn effects are neglected; vector potential (A) and current density $(\mathbf{J})$ have only the $z$-component; the core permeability is infinite; the PM is isotropic and the demagnetization curve is linear; eddy current effects are neglected; stator teeth, rotor cavities and PM have radial sides.

The subdomain analysis is performed for the equivalent model shown in Figure $1 \mathrm{~b}$. $\omega_{r} t$ is the rotation angle at time $t, \theta_{s i}$ is an initial angle of $i$-th slot, $\theta_{m 1,2 j}$ is an initial angle of spoke PM in $j$-th pole, $\theta_{m 3 j}$ is an initial angle of radial PM in $j$-th pole, $\theta_{c 1,2 j}$ is an initial angle of outer rotor cavities in $j$-th pole, and $\theta_{c 3 j}$ is an initial angle of inner rotor cavity in $j$-th pole. Note that $\phi_{s}$ is the slot width angle, $\phi_{s o}$ is the slot-opening width angle, $\phi_{m 1,2}$ is the spoke PM domain width angle, $\phi_{m 3}$ is the radial PM domain width angle, $\phi_{c 1,2}$ is the width angles of outer rotor cavities, and $\phi_{c 3}$ is the width angle of inner rotor cavity.

The field vectors $\mathbf{B}$ can be expressed as the magnetic material Equation [29]

$$
\mathbf{B}=\mu_{0} \mu_{r} \mathbf{H}+\mu_{0} \mathbf{M},
$$


where $\mu_{0}$ is the vacuum permeability, $\mu_{r}$ is the relative permeability of material, and $\mathbf{M}$ is the magnetization vector for PM. In this subdomain model, both radial and circumferential magnetized magnets are used. The radial magnetization has a rectangular pulse pattern, whereas the circumferential one has a constant pattern [33]:

$$
\begin{aligned}
M_{r j} & =\sum_{u}(-1)^{j+\frac{(u-1)}{2}}\left(\frac{-4}{u \pi} \frac{B_{r m}^{S u b}}{\mu_{0}}\right) \sin \left(\frac{u \pi \phi_{r m}}{\phi_{m 3}}\right) \sin \left(\frac{u \pi}{\phi_{m 3}}\left(\theta-\omega_{r} t-\theta_{m 3 j}+\frac{\phi_{m 3}}{2}\right)\right), \\
M_{\theta 1 j} & =\frac{B_{\theta m}^{S u b}}{\mu_{0}}(-1)^{j-1}, \quad M_{\theta 2 j}=-\frac{B_{\theta m}^{S u b}}{\mu_{0}}(-1)^{j-1},
\end{aligned}
$$

where $B_{r m}^{S u b}$ and $B_{\theta m}^{S u b}$ are, respectively, radial and circumferential remnant flux densities obtained by (1) and (2).

By applying the Ampere's law $(\nabla \times \mathbf{H}=J)$, Gauss's law $(\nabla \cdot \mathbf{B}=0)$ and vector potential definition $(\nabla \times \mathbf{A}=\mathbf{B})$ to (3), the Partial Differential Equation (PDE) can be obtained as

$$
\nabla^{2} \mathbf{A}=-\mu_{0} \mu_{r} \mathbf{J}-\mu_{0} \nabla \times \mathbf{M} .
$$

Using the assumptions and magnetization sources in each domain, the governing equations for each domain are derived such as:

$$
\begin{array}{ll}
\text { Subdomain } 1_{i}, & \nabla^{2} A_{1 i}=-\mu_{0} J_{i}, \\
\text { Subdomain } 2_{i}, & \nabla^{2} A_{2 i}=0, \\
\text { Subdomain 3, } & \nabla^{2} A_{3}=0, \\
\text { Subdomain } 4_{j}, & \nabla^{2} A_{4 j}=0, \\
\text { Subdomain } 5_{j}, & \nabla^{2} A_{5 j}=0, \\
\text { Subdomain } 6, & \nabla^{2} A_{6 j}=\frac{\mu_{0}}{r} \frac{\partial M_{r j}}{\partial \theta}, \\
\text { Subdomain } 7, & \nabla^{2} A_{7 j}=-\frac{\mu_{0}}{r} M_{\theta 1 j}, \\
\text { Subdomain } 8_{j}, & \nabla^{2} A_{8 j}=-\frac{\mu_{0}}{r} M_{\theta 2 j}, \\
\text { Subdomain } 9_{j}, & \nabla^{2} A_{9 j}=0,
\end{array}
$$

where $J_{i}$ is the current density in $i$-th slot. Laplace or Poisson equation is solved in each region (16) (24).

Subdomain $1_{i}$ (Coil),

$$
A_{i k}=a_{i k 0}+\frac{\mu_{0} J_{i}}{4}\left(2 r_{s o}^{2} \ln r-r^{2}\right)+\sum_{k}^{K}\left[a_{i k}\left(E_{k}\left(\frac{r}{r_{s o}}\right)^{F_{k}}+\left(\frac{r}{r_{s i}}\right)^{-F_{k}}\right)\right] \cos \left(F_{k}\left(\theta-\theta_{s i}+\phi_{s} / 2\right)\right)
$$

Subdomain $2_{i}$ (Slot-opening),

$$
A_{i g}=a_{i g 0}+b_{i g 0} \ln r+\sum_{g}^{G}\left[a_{i g}\left(\frac{r}{r_{s i}}\right)^{F_{g}}+b_{i g}\left(\frac{r}{r_{t}}\right)^{-F_{g}}\right] \cos \left(F_{g}\left(\theta-\theta_{s i}+\phi_{s o} / 2\right)\right)
$$

Subdomain 3 (Air-gap),

$$
A_{l}=\sum_{l}^{L}\left[a_{l}\left(\frac{r}{r_{t}}\right)^{l p}+b_{l}\left(\frac{r}{r_{a}}\right)^{-l p}\right] \cos (l p \theta)+\sum_{l}^{L}\left[c_{l}\left(\frac{r}{r_{t}}\right)^{l p}+d_{l}\left(\frac{r}{r_{a}}\right)^{-l p}\right] \sin (l p \theta)
$$


Subdomain 4 (Outer cavity 1),

$$
A_{j m}=a_{j m 0}+b_{j m 0} \ln r+\sum_{m}^{M}\left[a_{j m}\left(\frac{r}{r_{a}}\right)^{F_{m}}+b_{j m}\left(\frac{r}{r_{o b}}\right)^{-F_{m}}\right] \cos \left(F_{m}\left(\theta-\omega_{r} t-\theta_{c 1 j}+\phi_{c 1} / 2\right)\right)
$$

Subdomain 5 (Outer cavity 2),

$$
A_{j n}=a_{j n 0}+b_{j n 0} \ln r+\sum_{n}^{N}\left[a_{j n}\left(\frac{r}{r_{a}}\right)^{F_{n}}+b_{j n}\left(\frac{r}{r_{o b}}\right)^{-F_{n}}\right] \cos \left(F_{n}\left(\theta-\omega_{r} t-\theta_{c 2 j}+\phi_{c 2} / 2\right)\right)
$$

Subdomain 6 (Radial PM),

$$
A_{j u}=\sum_{u}^{U}\left[a_{j u}\left(\left(\frac{r}{r_{o b}}\right)^{F_{u}}+E_{u}\left(\frac{r}{r_{r m}}\right)^{-F_{u}}\right)+Y_{j u} r_{r m}\left(\frac{r}{r_{r m}}\right)^{-F_{u}}+A_{p j u} r\right] \cos \left(F_{u}\left(\theta-\omega_{r} t-\theta_{m 3 j}+\phi_{m 3} / 2\right)\right)
$$

Subdomain 7 (Circumferential PM 1),

$$
A_{j v}=a_{j v 0}+b_{j v 0} \ln r-\mu_{0} M_{\theta 1 j} r+\sum_{v}^{V}\left[a_{j v}\left(\frac{r}{r_{a}}\right)^{F_{v}}+b_{j v}\left(\frac{r}{r_{\theta m}}\right)^{-F_{v}}\right] \cos \left(F_{v}\left(\theta-\omega_{r} t-\theta_{m 1 j}+\phi_{m 1} / 2\right)\right)
$$

Subdomain 8 (Circumferential PM 2),

$$
A_{j w}=a_{j w 0}+b_{j w 0} \ln r-\mu_{0} M_{\theta 2 j} r+\sum_{w}^{W}\left[a_{j w}\left(\frac{r}{r_{a}}\right)^{F_{w}}+b_{j w}\left(\frac{r}{r_{\theta m}}\right)^{-F_{w}}\right] \cos \left(F_{w}\left(\theta-\omega_{r} t-\theta_{m 2 j}+\phi_{m 2} / 2\right)\right)
$$

Subdomain 9 (Inner cavity),

$$
A_{j h}=\sum_{h}^{H}\left[a_{j h}\left(\left(\frac{r}{r_{\theta m}}\right)^{F_{h}}+E_{h}\left(\frac{r}{r_{i b}}\right)^{-F_{h}}\right)\right] \cos \left(F_{h}\left(\theta-\omega_{r} t-\theta_{c 3 j}+\phi_{c 3} / 2\right)\right)
$$

The boundary conditions are the following:

$$
A_{\text {sub } 1}=A_{\text {sub } 2}, H_{\theta . s u b 1}=H_{\theta . s u b 2},
$$

where $A_{s u b 1}$ and $A_{s u b 2}$ are vector potentials in two adjacent subdomains, $H_{\theta . s u b 1}$ and $H_{\theta . s u b 2}$ are circumferential magnetic field strengths in two adjacent subdomains. The boundary conditions should be satisfied at each $\theta$-boundaries $\left(r=r_{s i}, r_{t}, r_{a}, r_{o b}, r_{\theta m}\right)$. Each calculation of the boundary conditions is described in Appendix A.

\subsection{Air-Gap Field and Torque}

At each time-step, the air-gap fields are obtained from the vector potential such that

$$
\begin{array}{r}
B_{r}(t, \theta)=\frac{1}{r} \frac{\partial A_{l}}{\partial \theta}=\sum_{l}\left[a_{l}\left(\frac{-l p}{r_{t}}\right)\left(\frac{r_{a i r}}{r_{t}}\right)^{l p-1}+b_{l}\left(\frac{-l p}{r_{a}}\right)\left(\frac{r_{a i r}}{r_{a}}\right)^{-l p-1}\right] \sin (l p \theta) \\
+\sum_{l}\left[c_{l}\left(\frac{l p}{r_{t}}\right)\left(\frac{r_{a i r}}{r_{t}}\right)^{l p-1}+d_{l}\left(\frac{l p}{r_{a}}\right)\left(\frac{r_{a i r}}{r_{a}}\right)^{-l p-1}\right] \cos (l p \theta)=\sum_{l} B_{r l}(t) \cos \left(l p \theta+\alpha_{r l}(t)\right), \\
B_{\theta}(t, \theta)=-\frac{\partial A_{l}}{\partial r}=\sum_{l}\left[a_{l}\left(\frac{-l p}{r_{t}}\right)\left(\frac{r_{a i r}}{r_{t}}\right)^{l p-1}+b_{l}\left(\frac{l p}{r_{a}}\right)\left(\frac{r_{a i r}}{r_{a}}\right)^{-l p-1}\right] \cos (l p \theta) \\
+\sum_{l}\left[c_{l}\left(\frac{-l p}{r_{t}}\right)\left(\frac{r_{a i r}}{r_{t}}\right)^{l p-1}+d_{l}\left(\frac{l p}{r_{a}}\right)\left(\frac{r_{a i r}}{r_{a}}\right)^{-l p-1}\right] \sin (l p \theta)=\sum_{l} B_{\theta l}(t) \cos \left(l p \theta+\alpha_{\theta l}(t)\right) .
\end{array}
$$


The instantaneous torque is derived from the Maxwell stress tensor using (26) and (27):

$$
T(t)=\frac{L_{z} r_{\text {air }}^{2} p}{\mu_{0}} \int_{0}^{2 \pi / p} B_{r}(t, \theta) B_{\theta}(t, \theta) d \theta=\sum_{l} T_{l}(t) \cos \left(\alpha_{r l}(t)-\alpha_{\theta l}(t)\right)
$$

where $T_{l}(t)=\frac{L_{z} r_{a i r}^{2} p}{\mu_{0}} B_{r l}(t) B_{\theta l}(t), L_{z}$ is stack length, and $r_{\text {air }}$ is center radius in air-gap.

Torque can be stated differently according to flux sources. Let the field densities be denoted by $B_{r}=B_{r . P M}+B_{r . A R}$ and $B_{\theta}=B_{\theta . P M}+B_{\theta . A R}$, where $B_{r . P M}$ is the radial field component created by the rotor PM, and $B_{r . A R}$ is the one driven by stator armature winding. The tangential components, $B_{\theta . P M}$ and $B_{\theta . A R}$ are also defined in the same manner. Then, the torque equation has four terms as follows [33]:

$$
T=\frac{L_{z} r_{\text {air }}^{2}}{\mu_{0}} \int_{0}^{2 \pi}\left(B_{r . P M} B_{\theta \cdot P M}+B_{r . P M} B_{\theta . A R}+B_{r . A R} B_{\theta \cdot P M}+B_{r . A R} B_{\theta \cdot A R}\right) d \theta .
$$

Note that $B_{r . P M} B_{\theta . P M}$ is the cogging torque which is independent of the stator current, and $B_{r . P M} B_{\theta \cdot A R}+$ $B_{\text {r.AR }} B_{\theta . P M}$ is the electromagnetic torque resulted from the interaction between PM and armature reaction fields. The last one, $B_{r . A R} B_{\theta . A R}$ is called reluctance torque since it is originated from the variation in the armature reaction field.

\subsection{Air-Gap Field Comparison between Subdomain and FEA}

To verify the accuracy of the subdomain results, their air-gap fields are compared with the FEA results under different current loading and angle conditions. Two results are compared first when only the PM is magnetized, and second when only the stator current is conducting. Note that $Q_{s} / G C D\left(Q_{s}, p\right)=12$, which is the number of slots per pole pair. Since the air-gap field does not have even harmonics, the most dominant harmonic numbers are found at $Q_{s} / G C D\left(Q_{s}, p\right)-1=11$ and $Q_{s} / G C D\left(Q_{s}, p\right)+1=13$.

Figure 2 shows the air-gap fields when only the PM is magnetized at $\omega_{r} t=0$ where the cogging torque is zero. It also shows magnitudes and phases of the field harmonics. Both the magnitude and phase of dominant harmonics show good agreements between the subdomain and FEA results. When the cogging torque is maximized at $\omega_{r} t=5.75^{\circ}$, similar results are obtained as shown in Figure 3.

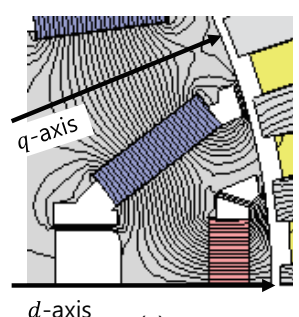

(a)
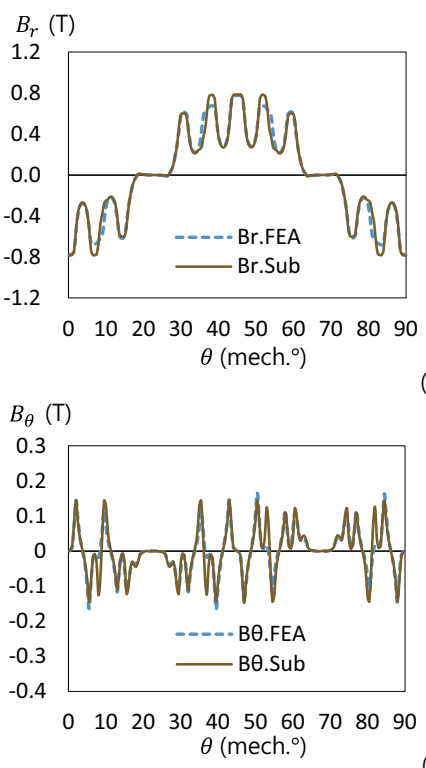

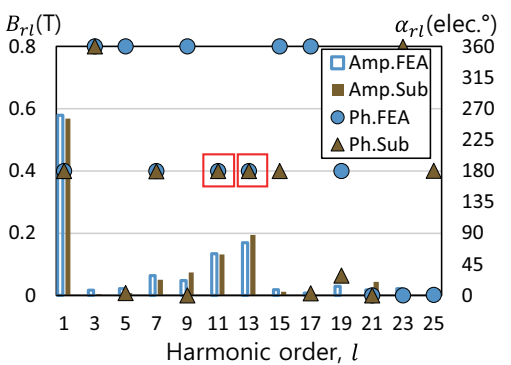

(b)

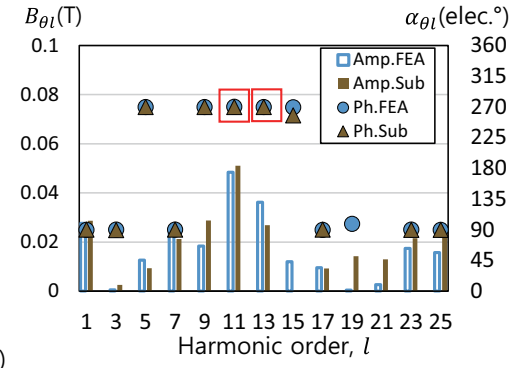

Figure 2. Comparisons of instantaneous air-gap fields when the cogging torque is zero: (a) flux lines, (b) radial fields, and (c) circumferential fields. 


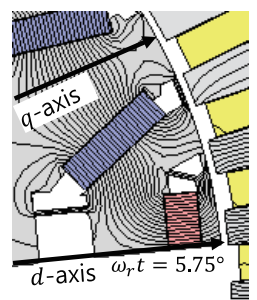

(a)
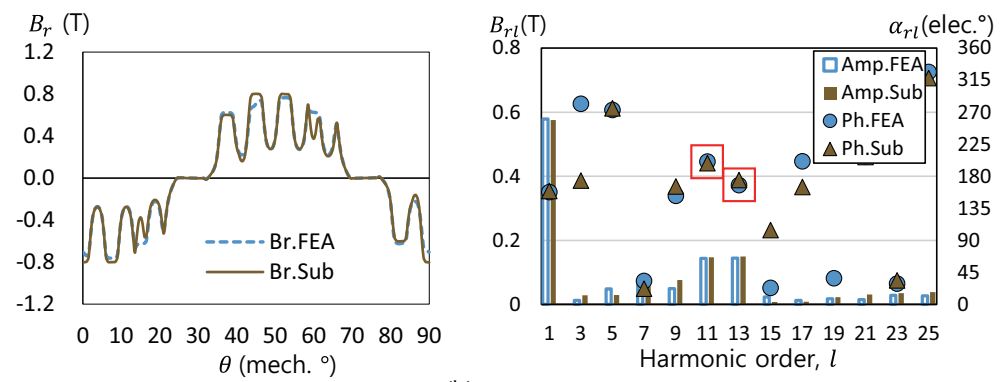

(b)

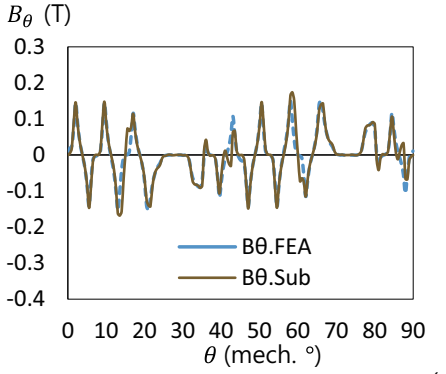

(c)

Figure 3. Comparisons of instantaneous air-gap fields when the cogging torque is maximum: (a) flux lines, (b) radial fields, and (c) circumferential fields.

The second part is shown in Figure 4, where the PMs are unmagnetized. Instead, current $i_{q}=185 \mathrm{~A}$ is injected to the stator coil with zero current angle. Note that the current angle $(\beta)$ is defined as the angle of the current vector with respect to the $q$-axis. When $\beta=0$, the current vector consists of only the $q$-axis component, and the $d$-axis current is equal to zero. Similarly to the previous results, the most dominant harmonic numbers are found at 11 and 13 orders. The subdomain and FEA results generally agree well, but there are some differences in the magnitude of the harmonics. However, the phases of the dominant harmonic components appear to be approximately the same.
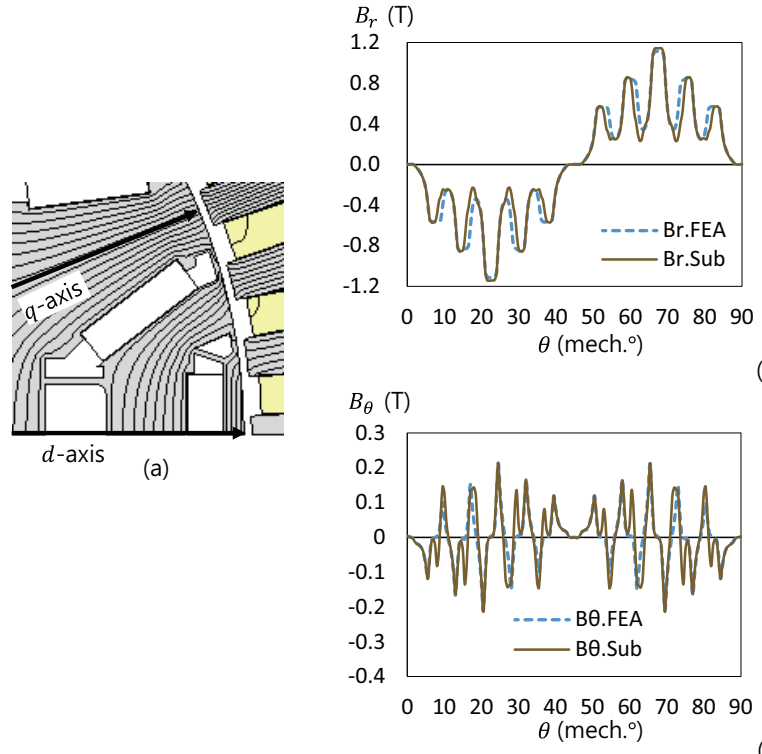

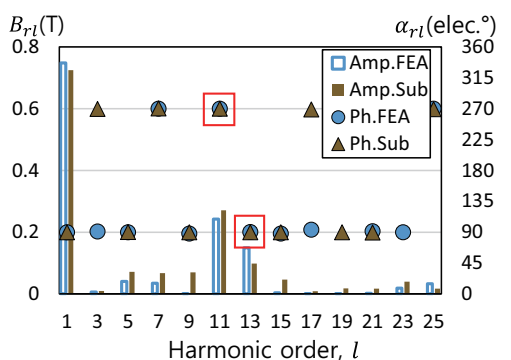

(b)

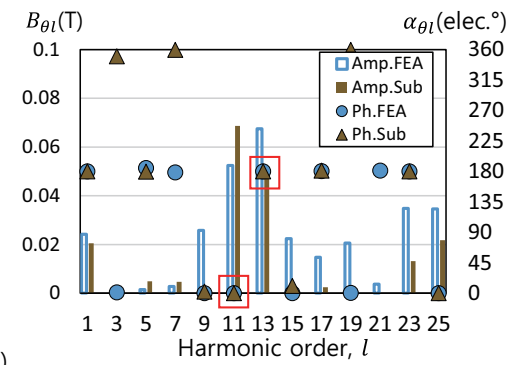

(c)

Figure 4. Comparisons of instantaneous air-gap fields when the reluctance torque ripple is zero: (a) flux lines, (b) radial fields, and (c) circumferential fields.

Similar results are obtained in Figure 5 for $\omega_{r} t=5.75^{\circ}$ with the largest torque ripple. Note again that the harmonic phases agree well. 


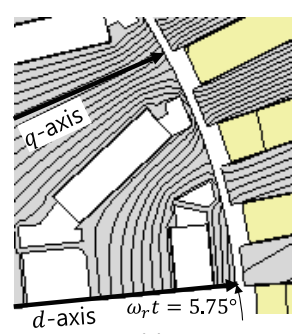

(a)
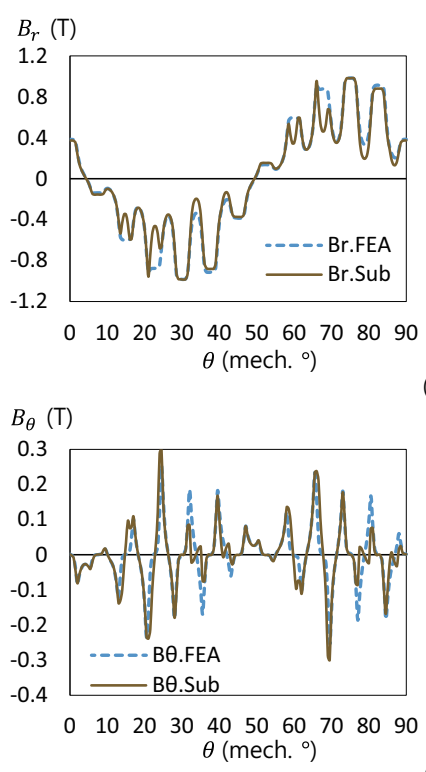

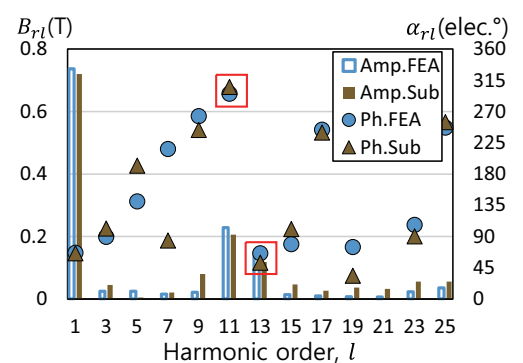

(b)

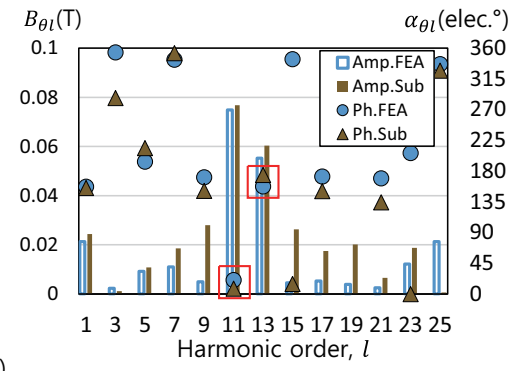

Figure 5. Comparisons of instantaneous air-gap fields when the reluctance torque ripple is maximum: (a) flux lines, (b) radial fields, and (c) circumferential fields.

\section{Torque Ripple and Harmonic Phase Condition}

According to (28), the phase difference $\alpha_{r l}-\alpha_{\theta l}$ of the field harmonics determines the $l$ th order torque component along with the magnitude, $T_{l}$. In the machine under consideration, the 11th and 13th harmonic components are dominant. Thus, we consider just the two harmonic components and let

$$
\Delta T(t)=T_{11}(t) \cos \left(\sigma_{11}(t)\right)+T_{13}(t) \cos \left(\sigma_{13}(t)\right),
$$

where $\sigma_{11}(t)=\alpha_{r 11}(t)-\alpha_{\theta 11}(t)$ and $\sigma_{13}(t)=\alpha_{r 13}(t)-\alpha_{\theta 13}(t)$. Note that $\Delta T$ represents approximately the reluctance torque ripple since the PM is unmagnetized. When the rotor rotates, $\Delta T$ varies as the flux paths change microscopically around the rotor cavities and bridges. Specifically, the magnitudes and phases of the space harmonics vary as the time-stepping progresses.

Figure 6 shows the time-stepping analysis of two different designs: Design A and Design B have the same arc $\phi_{d}=20^{\circ}$ for the $d$-axis flux barrier, but different arcs $\phi_{q}=5^{\circ}$ and $8^{\circ}$ for the $q$-axis channel. Figure $6 \mathrm{~b}, \mathrm{c}$ shows the magnitudes $T_{11}(t)$ and $T_{13}(t)$, and the phase differences $\sigma_{11}(t)$ and $\sigma_{11}(t)$. Comparing $T_{11}(t)$ and $T_{13}(t)$ of Design A and B, they, though different, are bounded in both cases. On the other hand, the phases difference, $\sigma_{11}(t)$ and $\sigma_{13}(t)$ of the space harmonics show completely different profiles in time. With Design A, the 11th and 13th have almost the same phase in time. Thereby, $T_{11}(t) \cos \left(\sigma_{11}(t)\right)$ and $T_{13}(t) \cos \left(\sigma_{13}(t)\right)$ are hardly canceled out, resulting in a large torque ripple $\Delta T$. In contrast, $\sigma_{11}(t)$ and $\sigma_{13}(t)$ of Design $B$ are almost $180^{\circ}$ out of phase, so that $T_{11}(t) \cos \left(\sigma_{11}(t)\right)$ and $T_{13}(t) \cos \left(\sigma_{13}(t)\right)$ tend to have opposite signs. Correspondingly, $\Delta T$ of Machine B is small. 

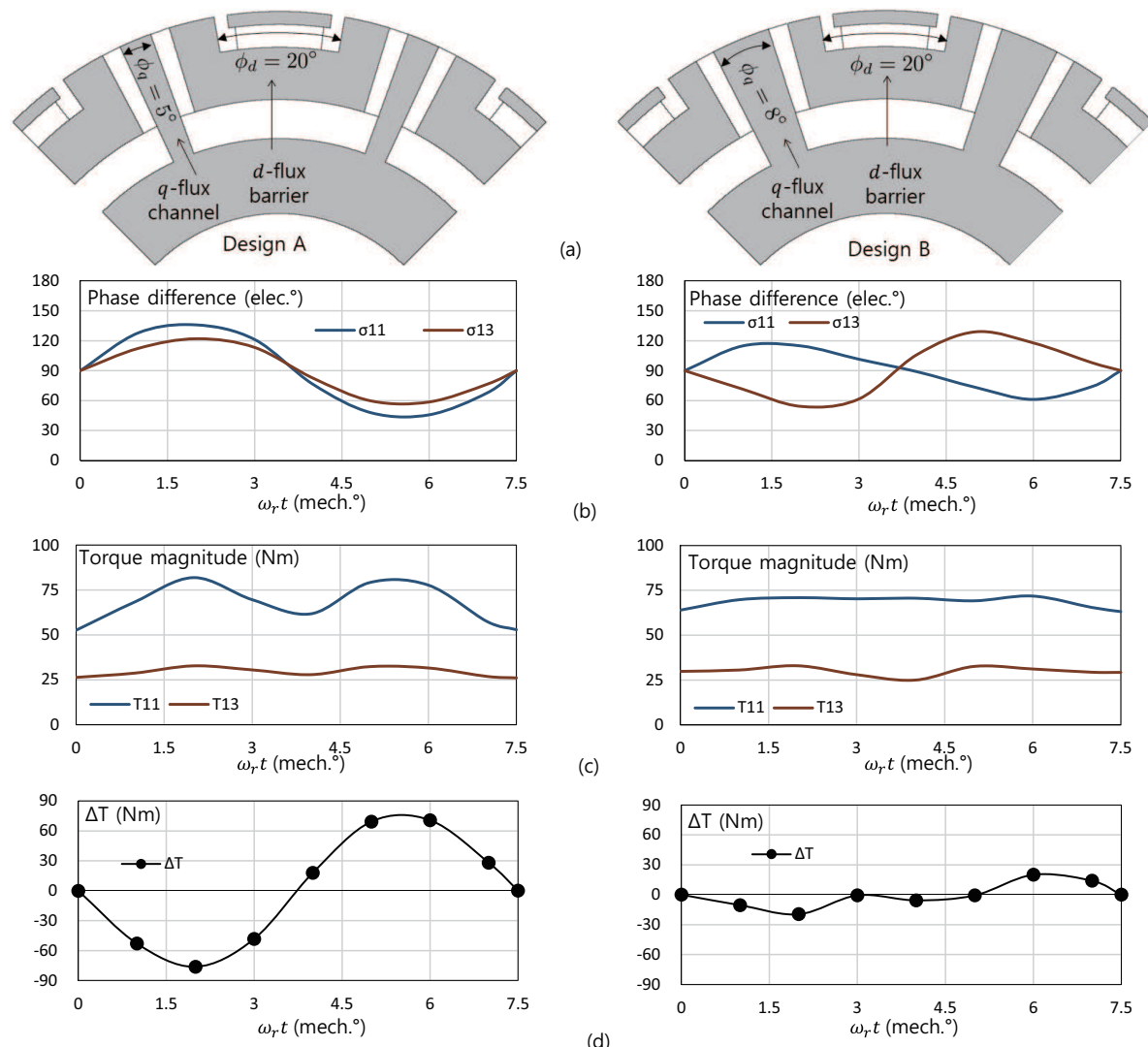

Figure 6. Comparisons of time-stepping plots in 11th and 13th torque components for Design A and B: (a) rotor configuration, (b) phase differences $\sigma_{11}$ and $\sigma_{13},(\mathbf{c})$ torque magnitude $T_{11}$ and $T_{13}$, (d) $\Delta T$.

Based on this observation, we are motivated to design the machine such that the signs of $\cos \left(\sigma_{11}(t)\right)$ and $\cos \left(\sigma_{13}(t)\right)$ are opposite. It is proposed in this paper as a torque ripple minimizing method that

$$
\sigma_{11}(t)+\sigma_{13}(t)=\pi \text { for all } 0 \leq \omega_{r} t \leq \frac{\pi}{Q_{s}}
$$

Thereby, the ripple minimizing design can be preceded by reducing the index

$$
\chi=\frac{1}{2} \int_{0}^{\frac{\pi}{\omega_{r} Q_{s}}}\left|\pi-\left(\sigma_{11}(t)+\sigma_{13}(t)\right)\right| d t \approx \frac{1}{2} \sum_{\omega_{r} t=0}^{\frac{\pi}{Q_{s}}}\left|\pi-\left(\sigma_{11}\left(\omega_{r} t\right)+\sigma_{13}\left(\omega_{r} t\right)\right)\right| \Delta \omega_{r} t .
$$

The closer $\chi$ to zero, the smaller the ripple under the assumption that $T_{11}(t)=T_{13}(t)$.

\section{Rotor Cavity Design Minimizing Torque Ripple}

The slot area is regarded as the magnitude of ampere-turn. However, a wide slot results in a narrow tooth width, increasing the teeth reluctance. Thereby, the stator magnetomotive force (MMF) must be balanced with the teeth reluctance. In most uniform slot machines, the tooth width is about the same as the slot opening, i.e., the slot angle is generally $\phi_{s}=\phi_{s o} \approx 0.5 \times 2 \pi / Q_{s}$. We let the angles of cavity bridges are fixed such that $\phi_{c 1,2}=2^{\circ}$ and $\phi_{m 1,2}=3^{\circ}$. As the design variables, we select the arcs of $d$-axis flux barrier and $q$-axis channel. Specifically, $\phi_{d}$ and $\phi_{q}$ shown in Figure 6a are considered the design variables. They are normalized by the slot pitch such that $\gamma_{q} \equiv \frac{\phi_{q}}{2 \pi / Q_{s}}$ and $\gamma_{d} \equiv \frac{\phi_{d}}{2 \pi / Q_{s}}$.

The proposed index $\chi$ is the error phase difference sum to the ideal phase difference when the rotor rotates half-slot. That is, it is an error accumulation value and its value is changed by the number of samples. In this work, $\chi$ on each design is calculated using 3 time-steps when rotation angle is $1,2,3^{\circ}$. The maximum harmonics for each subdomain are set as: $K=50, G=50, L=100$, $M=50, N=50, U=50, V=50, W=50$, and $H=50$. So, the computation time for subdomain 
analysis is 5 s under following computer system: Intel(R) Core(TM) i5-6600 CPU @ $3.30 \mathrm{GHz}$, installed memory 16.0 GB, and MATLAB program.

Figure 7a shows a level chart of $\chi$ over $\left(\gamma_{d}, \gamma_{q}\right)$ obtained by subdomain analysis. The minimum $\chi$ is found from the numerous combinations of $\left(\gamma_{d}, \gamma_{q}\right)$. Note that the contour lines represent equilevel curves, i.e., sets of the same $\chi$ values. The optimal design is obtained when $\gamma_{d}=2.67$ and $\gamma_{q}=1.06$. Figure $7 \mathrm{~b}$ shows a level chart of the torque ripple. Note that the minimum value is found at an almost same point predicted by the subdomain analysis. It shows clearly a strong correlation between the torque ripple and the phase criterion $\chi$.

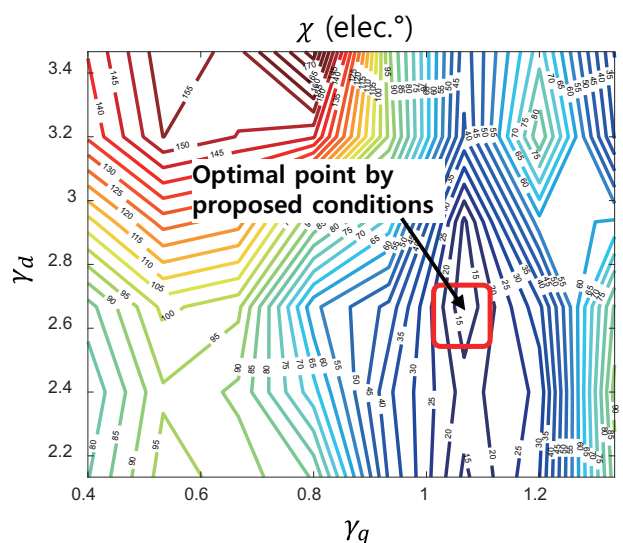

(a)

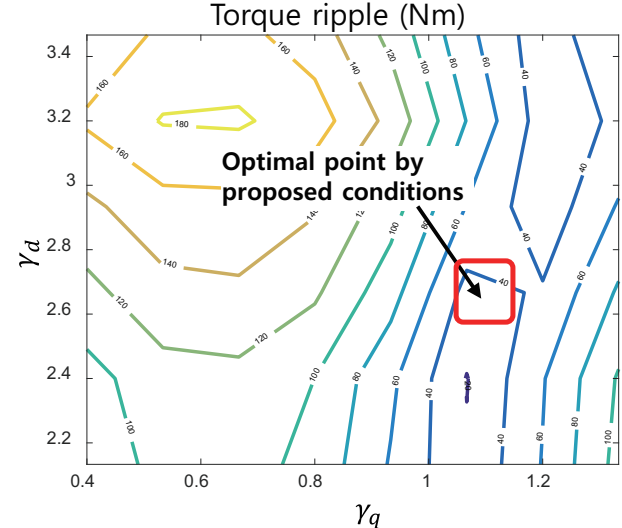

(b)

Figure 7. Optimization results via subdomain analysis: (a) level plot of $\chi$ and (b) level plot of torque ripple.

FEA for torque ripple analysis is set as following: 19,158 meshes, the rotation angle per step is $0.25^{\circ}$, the rotation angle is from 0 to $15^{\circ}$, and 61 time-steps. So, the computation time for FEA is $270 \mathrm{~s}$ using 2D magnetic field transient analysis of JMAG Designer.

The same optimization study was done via FEA with the practical model shown in Figure 1a under the same condition for PM and current. The equi-level contours are shown in Figure 8a,b. The general trend look similar as the one shown in Figure 7. Though a little differences are shown where $\gamma_{d}$ and $\gamma_{q}$ are small, the optimum point is found at the same location as the subdomain analysis. Furthermore, the time to find the optimal point is greatly reduced.

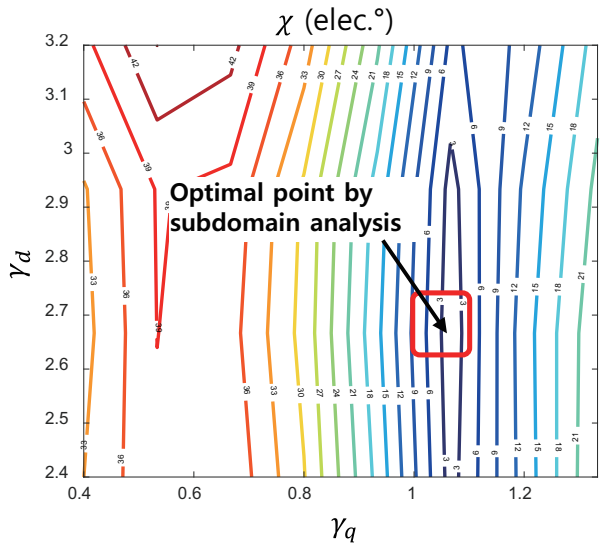

(a)

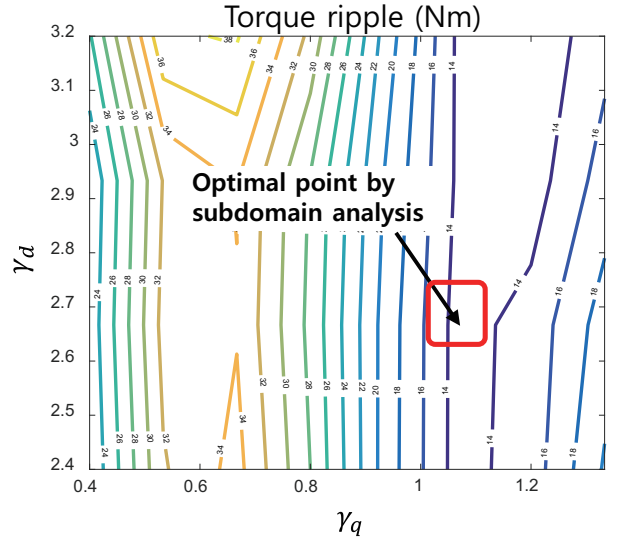

(b)

Figure 8. FEA optimization results when $\beta=0$ with PM unmagnetized: (a) level plot of $\chi$ and (b) level plot of torque ripple.

The above results are made with PM unmagnetized. Now, Figure 9a shows an optimization result by FEA when the PM is magnetized and current angle is $\beta \equiv \tan ^{-1}\left(-i_{d} / i_{q}\right)=44^{\circ}$. It also yields the same optimal point. Figure $9 \mathrm{~b}$ shows the torque wave plots. When it is compared with an initial design, torque ripple is shown to be reduced significantly. 


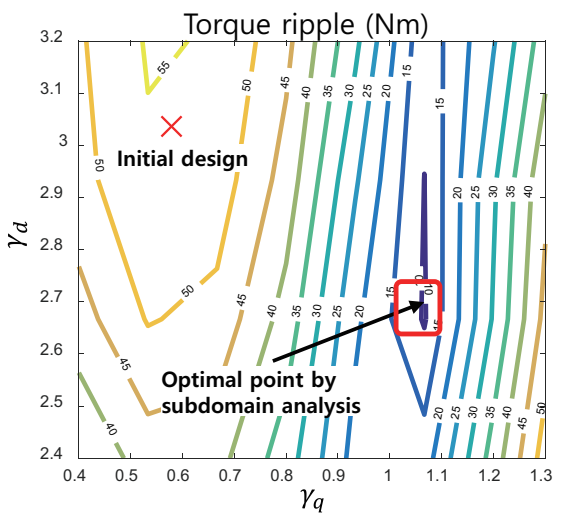

(a)

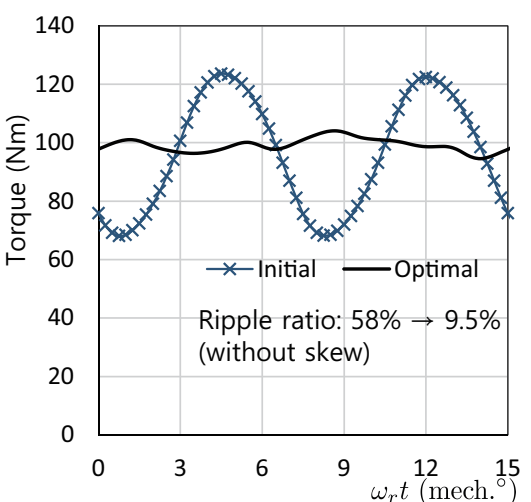

(b)

Figure 9. FEA optimization results when $\beta=44^{\circ}$ with PM magnetized: (a) level plot of torque ripple and (b) torque versus time.

\section{Prototype Motor and Experimental Results}

Figure 10a,b shows a delta-IPM rotor and uniform slot stator with a stranded winding. Experiments were done using a dynamometer as shown in Figure 10c. The test inverter was set up as follows: pulse width modulation switching frequency was $5 \mathrm{kHz}$, current control period was $200 \mu \mathrm{s}$, TMS320F28377 processor was utilized, and switch component was Infineon FF450R12KT4. Due to the low resolution of the torque sensor, the torque ripple were not measured. Line to line back electromotive force (EMF) is shown in Figure 11a,b.

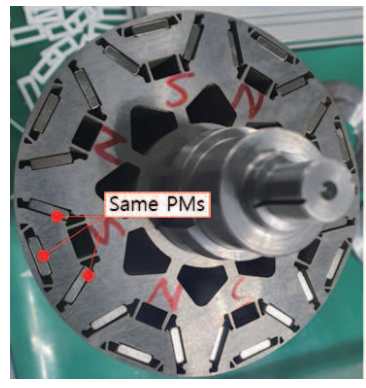

(a)

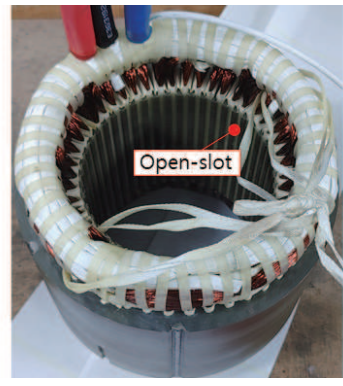

(b)

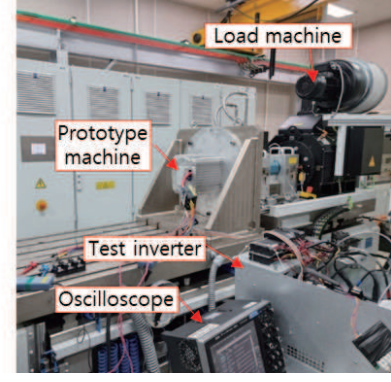

(c)

Figure 10. Prototype machine and experiment environment: (a) delta-IPM rotor, (b) uniform slot stator with a stranded winding, and (c) dynamometer test environment.

Figure 12a shows the current waveforms and $V_{d c}=70 \mathrm{~V}$ under a maximum load at a base speed. Figure $12 \mathrm{~b}$ shows a loaded result at the maximum speed, $7000 \mathrm{rpm}$.

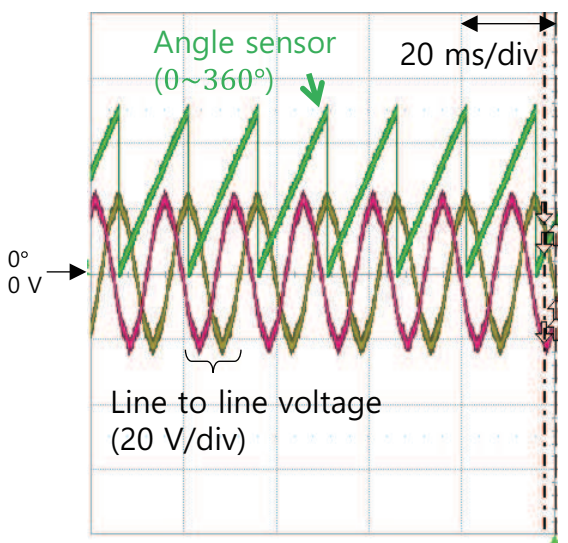

(a)

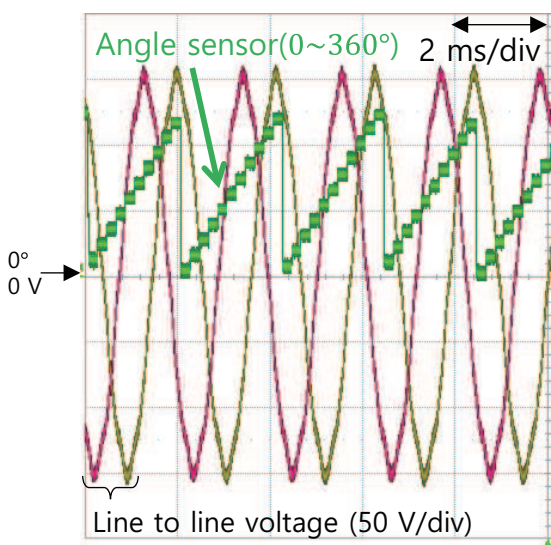

(b)

Figure 11. Back EMF waves: (a) 1000 rpm and (b) 7000 rpm. 
Figure 13 shows the comparisons between FEA results and experiment results. The back EMF magnitudes agree well in Figure 13a. The torque-speed performances are compared in Figure 13b. The same results are obtained below $5000 \mathrm{rpm}$, but less torque is generated in practice over $5000 \mathrm{rpm}$ due to stray and iron losses.

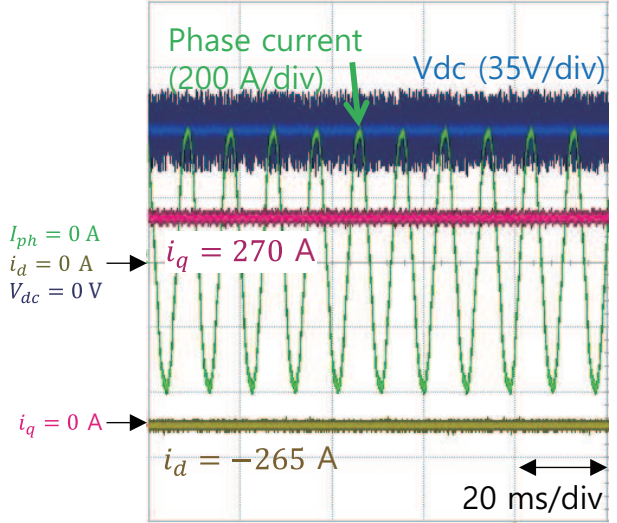

(a)

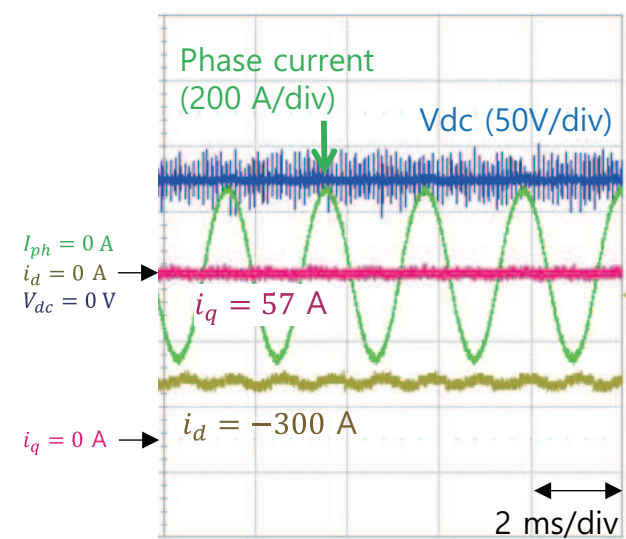

(b)

Figure 12. Maximum load experiments: (a) $90 \mathrm{Nm}$ at $1600 \mathrm{rpm}\left(i_{d}=-265 \mathrm{~A}, i_{q}=270 \mathrm{~A}\right)$ and (b) $16 \mathrm{Nm}$ at $7000 \mathrm{rpm}\left(i_{d}=-300 \mathrm{~A}, i_{q}=57 \mathrm{~A}\right)$.

The FEA-based efficiency is calculated as follows:

$$
\text { Efficiency }=\frac{T \omega_{r}}{T \omega_{r}+P_{c u}+P_{f e}+P_{\text {stray }}+P_{\text {mech }}},
$$

where $P_{c u}=\frac{3}{2} R_{p h} \sqrt{i_{d}^{2}+i_{q}^{2}}$ is the copper loss and $P_{f e}$ is the iron loss obtained by FEA. The stray loss is estimated as $10 \%$ of iron and copper losses, $P_{\text {stary }}=0.1 \times\left(P_{c u}+P_{f e}\right)$. The mechanical loss is assumed to be linear in speed and approximated as $P_{\text {mech }}=c \omega_{r}$ with $c=0.05 \mathrm{~W} / \mathrm{rpm}$ [34]. Meanwhile, the experimental efficiency is calculated as $\frac{T \omega_{r}}{P_{i n}}$, where $P_{i n}$ is the input power obtained by the power analyzer. Table 2 shows the comparison of the efficiency between the experimental and calculated results. Below the base speed, similar results are obtained. However, the difference is more pronounced in the field-weakening region, and the difference becomes larger as the speed increases. It seems to be caused by unmodeled AC loss of the coil and inaccurate stray losses.
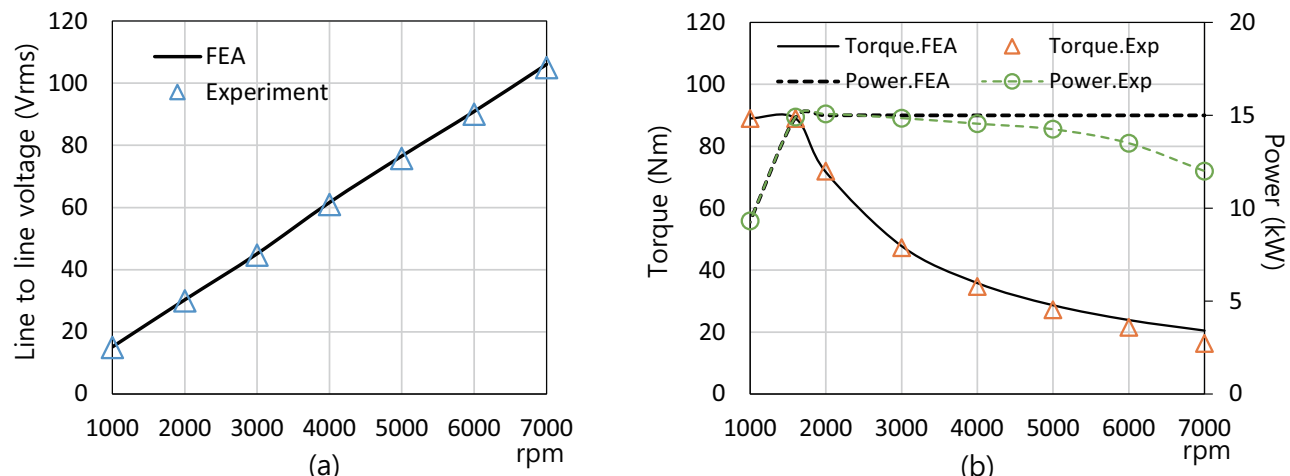

Figure 13. Comparison between FEA results and experiment results: (a) magnitudes of back EMF and (b) torque-speed curves. 
Table 2. Efficiency comparison.

\begin{tabular}{|c|c|c|c|c|c|c|c|}
\hline \multirow[b]{2}{*}{$\begin{array}{l}\text { Speed } \\
\text { (rpm) }\end{array}$} & \multirow[b]{2}{*}{$\begin{array}{l}i_{d} \\
\text { (A) }\end{array}$} & \multirow[b]{2}{*}{$\begin{array}{l}i_{q} \\
(\mathrm{~A})\end{array}$} & \multirow[b]{2}{*}{$\begin{array}{c}\text { Copper Loss } \\
P_{c u}(\mathrm{~W})\end{array}$} & \multicolumn{2}{|c|}{ Loss Estimates } & \multicolumn{2}{|r|}{ Experiment } \\
\hline & & & & $\begin{array}{c}\text { Iron Loss } \\
P_{f e}(\mathrm{~W})\end{array}$ & $\begin{array}{c}\text { Other Losses } \\
P_{\text {stray }}+P_{\text {mech }}(\mathrm{W})\end{array}$ & $\begin{array}{c}\text { Efficiency } \\
(\%)\end{array}$ & $\begin{array}{c}\text { Efficiency } \\
(\%)\end{array}$ \\
\hline 1000 & -265 & 270 & 1782 & 42.3 & 232.5 & 81.2 & 82.7 \\
\hline 1600 & -265 & 270 & 1782 & 80.7 & 266.3 & 87.0 & 88.8 \\
\hline 2000 & -324 & 194 & 1782 & 85.2 & 286.6 & 87.7 & 89.6 \\
\hline 3000 & -357 & 123 & 1782 & 98.5 & 338.1 & 87.2 & 84.8 \\
\hline 4000 & -347 & 93 & 1759 & 123.6 & 388.4 & 85.2 & 81.4 \\
\hline 5000 & -320 & 80 & 1412 & 152.1 & 406.6 & 86.0 & 79.3 \\
\hline
\end{tabular}

\section{Conclusions}

An IPM machine is developed with uniform stator slots for small EVs. This type machine has the advantage of reducing the winding cost, since a rectangular coil can be inserted from the inner wall side without an expensive coil inserter or copper welding machine. However, in general, there is a problem of large torque ripple. According to the Maxwell stress tensor, the torque is obtained as an integral sum of $B_{r} \times B_{\theta}$ in the air-gap. Therefore, the phase differences of the radial and circumferential harmonic fields remain as the ripple components. When the number of slots per pole pair is 12 , the phase differences of 11th and 13th are dominant. If the two harmonic components cancel each other, the torque ripple is minimized. Specifically, they should have $180^{\circ}$ difference in order to minimize the torque ripple. The desired cancellation condition is formulated as an index and the minimizing solution is found by using subdomain analysis. The similar optimal solution was also verified by FEA. However, the subdomain analysis took $5 \mathrm{~s}$ to compute for each design, whereas FEA took $270 \mathrm{~s}$. A prototype motor was manufactured and its performance was verified through dynamometer test.

Author Contributions: Conceptualization, M.L. and K.N.; methodology, M.L.; software, M.L. and Y.H.; validation, M.L. and Y.H.; formal analysis, M.L.; investigation, Y.H.; writing—original draft preparation, M.L.; writing-review and editing, K.N.; visualization, M.L.; supervision, K.N.; funding acquisition, K.N. All authors have read and agreed to the published version of the manuscript.

Funding: This work was supported by the Technology development Program(1425142212) funded by the Ministry of SMEs and Startups (MSS, Korea).

Conflicts of Interest: The authors declare no conflict of interest.

\section{Abbreviations}

The following abbreviations are used in this manuscript:

EV Electric vehicle

MEC Magnetic equivalent circuit

IPM Interior permanent magnet

SPM Surface permanent magnet

FEA Finite element analysis

MMF Magnetomotive force

EMF Electromotive force

\section{Appendix A. Boundary Conditions}

At $r=r_{s i}$ and $\theta \in\left[\theta_{s i}-\frac{\phi_{s o}}{2}, \theta_{c i}+\frac{\phi_{s o}}{2}\right]$, continuity of vector potential $\left(A_{i k}=A_{i g}\right)$ yields

$$
\begin{array}{r}
a_{i k 0}+\frac{\mu_{0} J_{i}}{4}\left(2 r_{s o}^{2} \ln r_{s i}-r_{s i}^{2}\right)=\left[a_{i g 0}+b_{i g 0} \ln r_{s i}\right] \frac{\phi_{s o}}{\phi_{s}}+\sum_{g}^{G}\left[a_{i g}+b_{i g} E_{g}\right] \eta_{i g o}, \\
a_{i k}\left(E_{k}^{2}+1\right)=\left[a_{i g 0}+b_{i g 0} \ln r_{s i}\right] \eta_{i k 0}+\left[a_{i g}+b_{i g} E_{g}\right] \eta_{i k g},
\end{array}
$$


where $E_{k}=\left(\frac{r_{s i}}{r_{s o}}\right)^{F_{k}}, F_{k}=\frac{k \pi}{\phi_{s}}, E_{g}=\left(\frac{r_{s i}}{r_{t}}\right)^{F_{g}}$, and $F_{g}=\frac{g \pi}{\phi_{s o}}$,

$\eta_{i g o}=\frac{1}{\phi_{s}} \int_{\theta_{s i}-\frac{\phi_{s o}}{2}}^{\theta_{s i}+\frac{\phi_{s o}}{2}} \cos \left(F_{g}\left(\theta-\theta_{s i}+\frac{\phi_{s o}}{2}\right) d \theta, \eta_{i k o}=\frac{2}{\phi_{s}} \int_{\theta_{s i}-\frac{\phi_{s 0}}{2}}^{\theta_{s i}+\frac{\phi_{s o}}{2}} \cos \left(F_{k}\left(\theta-\theta_{s i}+\frac{\phi_{s}}{2}\right) d \theta\right.\right.$,

$\eta_{i g k}=\frac{2}{\phi_{s}} \int_{\theta_{s i}-\frac{\phi_{s o}}{2}}^{\theta_{s i}+\frac{\phi_{s o}^{2}}{2}} \cos \left(F_{g}\left(\theta-\theta_{s i}+\frac{\phi_{s o}}{2}\right) \cos \left(F_{k}\left(\theta-\theta_{s i}+\frac{\phi_{s}}{2}\right) d \theta\right.\right.$,

In the same way, continuity of tangential magnetic field strength $\left(H_{\theta i k}=H_{\theta i g}\right)$ gives

$$
\begin{array}{r}
\frac{\mu_{0} J_{i}}{2}\left(r_{s o}^{2}-r_{s i}^{2}\right)+\sum_{k}^{K}\left[a_{i k} F_{k}\left(E_{k}^{2}-1\right)\right] \frac{\phi_{s}}{2 \phi_{s o}} \eta_{i k 0}=b_{i g 0}, \\
\frac{\mu_{0} J_{i}}{2}\left(r_{s o}^{2}-r_{s i}^{2}\right) \frac{2 \phi_{s}}{\phi_{s o}} \eta_{i g 0}+\sum_{k}\left[a_{i k} F_{k}\left(E_{k}^{2}-1\right)\right] \frac{\phi_{s}}{\phi_{s o}} \eta_{i g k}=a_{i g} F_{g}+b_{i g}\left(-F_{g} E_{g}\right) .
\end{array}
$$

At $r=r_{t}$ and $\theta \in\left[\theta_{s i}-\frac{\phi_{s o}}{2}, \theta_{c i}+\frac{\phi_{s o}}{2}\right]$, continuity of vector potential $\left(A_{i g}=A_{l}\right)$ yields

$$
\begin{aligned}
a_{i g 0}+b_{i g 0} \ln r_{t} & =\sum_{l}^{L}\left[\left(a_{l}+b_{l} E_{l}\right) \eta_{i l 0}+\left(c_{l}+d_{l} E_{l}\right) \zeta_{i l 0}\right], \\
a_{i g} E_{g}+b_{i g} & =\sum_{l}^{L}\left[\left(a_{l}+b_{l} E_{l}\right) \eta_{i g l}+\left(c_{l}+d_{l} E_{l}\right) \zeta_{i g l}\right],
\end{aligned}
$$

where $E_{l}=\left(\frac{r_{a}}{r_{t}}\right)^{l p}, \eta_{i l 0}=\frac{1}{\phi_{s o}} \int_{\theta_{s i}-\frac{\phi_{s o}^{2}}{2}}^{\theta_{s i}} \cos (l p \theta) d \theta, \zeta_{i l 0}=\frac{1}{\phi_{s o}} \int_{\theta_{s i}-\frac{\phi_{s o}}{2}}^{\theta_{s i}} \frac{\phi_{s o}}{2} \sin (l p \theta) d \theta$,

$\eta_{i g l}=\frac{2}{\phi_{s o}} \int_{\theta_{s i}-\frac{-\phi_{s o}^{2}}{\theta_{s i}}}^{\theta_{i}} \cos (l p \theta) \cos \left(F_{g}\left(\theta-\theta_{s i}+\frac{\phi_{s o}}{2}\right)\right) d \theta$,

$\zeta_{\text {igl }}=\frac{2}{\phi_{s o}} \int_{\phi_{s i}-\frac{\phi_{s o}^{2}}{2}}^{\phi_{s i}+\frac{\phi_{s 0}}{2}} \sin (l p \theta) \cos \left(F_{g}\left(\theta-\theta_{s i}+\frac{\phi_{s o}}{2}\right)\right) d \theta$.

In the same way, continuity of tangential magnetic field strength $\left(\sum_{i} H_{\theta i g}=H_{\theta l}\right)$ gives

$$
\begin{aligned}
& \sum_{i}^{Q_{s}} b_{i g 0} \frac{p \phi_{s o}}{\pi} \eta_{i l 0}+\sum_{i}^{Q_{s}} \sum_{g}^{G}\left(a_{i g} F_{g} E_{g}-b_{i g} F_{g}\right) \frac{p \phi_{s o}}{2 \pi} \eta_{i g l}=a_{l} l p+b_{l}(-l p) E_{l} \\
& \sum_{i}^{Q_{s}} b_{i g 0} \frac{p \phi_{s o}}{\pi} \zeta_{i l 0}+\sum_{i}^{Q_{s}} \sum_{g}^{G}\left(a_{i g} F_{g} E_{g}-b_{i g} F_{g}\right) \frac{p \phi_{s o}}{2 \pi} \zeta_{i g l}=c_{l} l p+d_{l}(-l p) E_{l} .
\end{aligned}
$$

At $r=r_{a}$ and $\theta \in\left[0, \frac{2 \pi}{p}\right]$, continuity of vector potential $\left(A_{l}=A_{j m}\right)$ yields

$$
\begin{gathered}
\sum_{l}^{L}\left(a_{l} E_{l}+b_{l}\right) \eta_{j c 1}+\sum_{l}^{L}\left(c_{l} E_{l}+d_{l}\right) \zeta_{j c 1}=a_{j m 0}+b_{j m 0} \ln r_{a} \\
\sum_{l}^{L}\left(a_{l} E_{l}+b_{l}\right) \eta_{j l m}+\sum_{l}^{L}\left(c_{l} E_{l}+d_{l}\right) \zeta_{j l m}=a_{j m}+b_{j m} E_{m}
\end{gathered}
$$

where $E_{m}=\left(\frac{r_{a}}{r_{o b}}\right)^{F_{m}}, F_{m}=\frac{m \pi}{\phi_{c 1}}$.

Continuity of vector potential $\left(A_{l}=A_{j n}\right)$ yields

$$
\begin{gathered}
\sum_{l}^{L}\left(a_{l} E_{l}+b_{l}\right) \eta_{j c 1}+\sum_{l}^{L}\left(c_{l} E_{l}+d_{l}\right) \zeta_{j c 1}=a_{j m 0}+b_{j m 0} \ln r_{a} \\
\sum_{l}^{L}\left(a_{l} E_{l}+b_{l}\right) \eta_{j l m}+\sum_{l}^{L}\left(c_{l} E_{l}+d_{l}\right) \zeta_{j l m}=a_{j m}+b_{j m} E_{m}
\end{gathered}
$$

where $E_{n}=\left(\frac{r_{a}}{r_{o b}}\right)^{F_{n}}, F_{n}=\frac{n \pi}{\phi_{c 2}}$. Continuity of vector potential $\left(A_{l}=A_{j v}\right)$ yields

$$
\begin{array}{r}
\sum_{l}^{L}\left(a_{l} E_{l}+b_{l}\right) \eta_{j m 1}+\sum_{l}^{L}\left(c_{l} E_{l}+d_{l}\right) \zeta_{j m 1}=a_{j v 0}+b_{j v 0} \ln r_{a}-\mu_{0} r_{a} M_{j \theta 1}, \\
\sum_{l}^{L}\left(a_{l} E_{l}+b_{l}\right) \eta_{j l v}+\sum_{l}^{L}\left(c_{l} E_{l}+d_{l}\right) \zeta_{j l v}=a_{j v}+b_{j v} E_{v},
\end{array}
$$


where $E_{v}=\left(\frac{r_{a}}{r_{o b}}\right)^{F_{v}}, F_{v}=\frac{v \pi}{\phi_{m 1}}$. Continuity of vector potential $\left(A_{l}=A_{j w}\right)$ yields

$$
\begin{gathered}
\sum_{l}^{L}\left(a_{l} E_{l}+b_{l}\right) \eta_{j m 2}+\sum_{l}^{L}\left(c_{l} E_{l}+d_{l}\right) \zeta_{j m 2}=a_{j w 0}+b_{j w 0} \ln r_{a}-\mu_{0} r_{a} M_{j \theta 2,} \\
\sum_{l}^{L}\left(a_{l} E_{l}+b_{l}\right) \eta_{j l w}+\sum_{l}^{L}\left(c_{l} E_{l}+d_{l}\right) \zeta_{j l w}=a_{j w}+b_{j w} E_{w},
\end{gathered}
$$

where $E_{w}=\left(\frac{r_{a}}{r_{o b}}\right)^{F_{w}}, F_{w}=\frac{w \pi}{\phi_{m 2}}, \eta_{j c 1}=\frac{1}{\phi_{c 1}} \int_{\omega_{r} t+\theta_{c 1 j}-\frac{\phi_{c 1}}{2}}^{\omega_{r} t+\theta_{c 1}+\frac{\phi_{c 1}}{2}} \cos (l p \theta) d \theta, \zeta_{j c 1}=\frac{1}{\phi_{c 1}} \int_{\omega_{r} t+\theta_{c 1 j}-\frac{\phi_{c 1}}{2}}^{\omega_{r} t+\theta_{c 1 j}+\frac{\phi_{c 1}}{2}} \sin (\operatorname{lp} \theta) d \theta$, $\eta_{j l m}=\frac{2}{\phi_{c 1}} \int_{\omega_{r} t+\theta_{c 1 j}-\frac{\phi_{c 1}}{2}}^{\omega_{1} t+\theta_{c 1}+\frac{\phi_{c 1}}{2}} \cos (l p \theta) \cos \left(F_{m}\left(\theta-\phi_{c 1 j}+\frac{\phi_{c 1}}{2}\right)\right) d \theta$,

$\zeta_{j l m}=\frac{2}{\phi_{c 1}} \int_{\omega_{r} t+\theta_{c 1 j}-\frac{\phi_{c 1}}{2}}^{\omega_{r} t+\theta_{c 1}+\frac{\phi_{c 1}}{2}} \sin (l p \theta) \cos \left(F_{m}\left(\theta-\phi_{c 1 j}+\frac{\phi_{c 1}}{2}\right)\right) d \theta$, where $\theta_{c 1 j}, \phi_{c 1}$, and $F_{m}$ are changed to the corresponding coefficients of subdomain $4,5,7,8$.

In the same way, continuity of tangential magnetic field strength $\left(H_{\theta l}=\sum_{j}^{2 p}\left[H_{\theta j m}+H_{\theta j n}+\right.\right.$ $\left.\left.H_{\theta j v}+H_{\theta j w}\right]\right)$ gives

$$
\begin{array}{r}
a_{l} l p E_{l}+b_{l}(-l p)=\sum_{j}^{2 p}\left[b_{j m 0} \frac{p \phi_{c 1}}{\pi} \eta_{j c 1}+\sum_{m}^{M}\left(a_{j m} F_{m}-b_{j m} F_{m} E_{m}\right) \frac{p \phi_{c 1}}{2 \pi} \eta_{j l m}\right. \\
+b_{j n 0} \frac{p \phi_{c 2}}{\pi} \eta_{j c 2}+\sum_{n}^{N}\left(a_{j n} F_{n}-b_{j n} F_{n} E_{n}\right) \frac{p \phi_{c 2}}{2 \pi} \eta_{j l n}+b_{j v 0} \frac{p \phi_{m 1}}{\mu_{m} \pi} \eta_{j m 1}+\sum_{v}^{V}\left(a_{j v} F_{v}-b_{j v} F_{v} E_{v}\right) \frac{p \phi_{m 1}}{2 \pi} \eta_{j l v} \\
\left.+b_{j w 0} \frac{p \phi_{m 2}}{\mu_{m} \pi} \eta_{j m 2}+\sum_{w}^{W}\left(a_{j w} F_{w}-b_{j w} F_{w} E_{w}\right) \frac{p \phi_{m 2}}{2 \pi} \eta_{j l w}\right], \\
c_{l} l p E_{l}+d_{l}(-l p)=\sum_{j}^{2 p}\left[b_{j m 0} \frac{p \phi_{c 1}}{\pi} \zeta_{j c 1}+\sum_{m}^{M}\left(a_{j m} F_{m}-b_{j m} F_{m} E_{m}\right) \frac{p \phi_{c 1}}{2 \pi} \zeta_{j l m}\right. \\
+b_{j n 0} \frac{p \phi_{c 2}}{\pi} \zeta_{j c 2}+\sum_{n}^{N}\left(a_{j n} F_{n}-b_{j n} F_{n} E_{n}\right) \frac{p \phi_{c 2}}{2 \pi} \zeta_{j l n}+b_{j v 0} \frac{p \phi_{m 1}}{\mu_{m} \pi} \zeta_{j m 1}+\sum_{v}^{V}\left(a_{j v} F_{v}-b_{j v} F_{v} E_{v}\right) \frac{p \phi_{m 1}}{2 \pi} \zeta_{j l v} \\
\left.+b_{j w 0} \frac{p \phi_{m 2}}{\mu_{m} \pi} \zeta_{j m 2}+\sum_{w}^{W}\left(a_{j w} F_{w}-b_{j w} F_{w} E_{w}\right) \frac{p \phi_{m 2}}{2 \pi} \zeta_{j l w}\right] .
\end{array}
$$

At $r=r_{o b}$ and $\theta \in\left[\omega_{r} t+\theta_{m 3 j}-\frac{\phi_{r m}}{2}, \omega_{r} t+\theta_{m 3 j}+\frac{\phi_{r m}}{2}\right]$, continuity of vector potential $\left(A_{j m}=A_{j u}\right.$ and $A_{j n}=A_{j u}$ ) yields

$$
\begin{aligned}
a_{j m 0}+b_{j m 0} \ln r_{o b} & =\sum_{u}^{U}\left[a_{j u}\left(1+E_{u}^{2}\right)+r_{r m} E_{u} G_{j u}+r_{o b} A_{p j u}\right] \rho_{j c 1}, \\
a_{j m} E_{m}+b_{j m}= & \sum_{u}^{U}\left[a_{j u}\left(1+E_{u}^{2}\right)+r_{r m} E_{u} G_{j u}+r_{o b} A_{p j u}\right] \rho_{j m u}, \\
a_{j n 0}+b_{j n 0} \ln r_{o b} & =\sum_{u}^{U}\left[a_{j u}\left(1+E_{u}^{2}\right)+r_{r m} E_{u} G_{j u}+r_{o b} A_{p j u}\right] \rho_{j c 2}, \\
a_{j n} E_{n}+b_{j n} & =\sum_{u}^{U}\left[a_{j u}\left(1+E_{u}^{2}\right)+r_{r m} E_{u} G_{j u}+r_{o b} A_{p j u}\right] \rho_{j n u},
\end{aligned}
$$

where $E_{u}=\left(\frac{r_{m}}{r_{o b}}\right)^{F_{u}}, F_{u}=\frac{u \pi}{\phi_{m 3}}, Y_{j u}=\frac{\mu_{0}}{F_{u}^{2}-1}(-1)^{j+(u-1) / 2}\left(\frac{4 \pi}{u}\right)\left(\frac{B_{r m b}^{\text {sub }}}{\mu_{0}}\right) \sin \left(\frac{u \pi \phi_{r m}}{\phi_{m 3}}\right)$, $A_{p j u}=\frac{\mu_{0} F_{u}}{F_{u}^{2}-1}(-1)^{j+(u-1) / 2}\left(\frac{4 \pi}{u}\right)\left(\frac{B_{r m b}^{S u b}}{\mu_{0}}\right) \sin \left(\frac{u \pi \phi_{r m}}{\phi_{m 3}}\right)$,

$\rho_{j c 1}=\frac{1}{\phi_{c 1}} \int_{\omega_{r} t+\theta_{c 1 j}-\frac{\phi_{c 1}}{2}}^{\omega_{r} t+\theta_{c 1}+\frac{\phi_{c 1}}{2}} \cos \left(F_{u}\left(\theta-\omega_{r} t-\theta_{m 3 j}+\frac{\phi_{m 3}}{2}\right)\right) d \theta$,

$\rho_{j m u}=\frac{2}{\phi_{c 1}} \int_{\omega_{r} t+\theta_{c 1 j}-\frac{\phi_{c 1}}{2}}^{\omega_{r} t+\theta_{c 1}+\frac{\phi_{c 1}}{2}} \cos \left(F_{m}\left(\theta-\omega_{r} t-\theta_{c 1 j}+\frac{\phi_{c 1}}{2}\right)\right) \times \cos \left(F_{u}\left(\theta-\omega_{r} t-\theta_{m 3 j}+\frac{\phi_{m 3}}{2}\right)\right) d \theta$.

In the same way, continuity of tangential magnetic field strength $\left(H_{\theta j m}+H_{\theta j n}=H_{\theta j u}\right)$ gives

$$
\begin{array}{r}
b_{j m 0} \frac{2 \phi_{c 1}}{\phi_{m 3}} \rho_{c 1}+\sum_{m}^{M}\left[a_{j m} F_{m}^{2}-b_{j m} F_{m}\right] \frac{\phi_{c 1}}{\phi_{m 3}} \rho_{j m u} \\
+b_{j n 0} \frac{2 \phi_{c 2}}{\phi_{m 3}} \rho_{c 2}+\sum_{n}^{N}\left[a_{j n} F_{n}^{2}-b_{j n} F_{n}\right] \frac{\phi_{c 2}}{\phi_{m 3}} \rho_{j n u} \\
=a_{j u} \frac{F_{u}}{\mu_{m}}\left(1-E_{u}^{2}\right)-\frac{r_{r m} F_{u} E_{u}}{\mu_{m}} G_{j u}+\frac{r_{o b}}{\mu_{m}} A_{p j u} .
\end{array}
$$


At $r=r_{\theta m}$ and $\theta \in\left[\omega_{r} t+\theta_{c 3 j}-\frac{\phi_{c 3}}{2}, \omega_{r} t+\theta_{c 3 j}+\frac{\phi_{c 3}}{2}\right]$, continuity of vector potential $\left(A_{j v}=A_{j h}\right.$ and $\left.A_{j w}=A_{j h}\right)$ yields

$$
\begin{array}{r}
a_{j v 0}+b_{j v 0} \ln r_{\theta m}-\mu_{0} M_{\theta 1 j} r_{\theta m}=\sum_{h}^{H} a_{j h}\left(1+E_{h}^{2}\right) \rho_{j m 1}, \\
a_{j w 0}+b_{j w 0} \ln r_{\theta m}-\mu_{0} M_{\theta 2 j} r_{\theta m}=\sum_{h}^{H} a_{j h}\left(1+E_{h}^{2}\right) \rho_{j m 2}, \\
a_{j v} E_{v}+b_{j v}=\sum_{h}^{H} a_{j h}\left(1+E_{h}^{2}\right) \rho_{j v h}, a_{j v} E_{w}+b_{j w}=\sum_{h}^{H} a_{j h}\left(1+E_{h}^{2}\right) \rho_{j w h},
\end{array}
$$

where $E_{h}=\left(\frac{r_{i b}}{r_{\theta m}}\right)^{F_{h}}, F_{h}=\frac{h \pi}{\phi_{c 3}}$,

$$
\begin{aligned}
& \rho_{j m 1}=\frac{1}{\phi_{m 1}} \int_{\omega_{r} t+\theta_{m 1 j}-\frac{\phi_{m 1}}{2}}^{\omega_{r} t+\theta_{m 1}+\frac{\phi_{m 1}}{2}} \cos \left(F_{h}\left(\theta-\omega_{r} t-\theta_{j c 3}+\frac{\phi_{c 3}}{2}\right)\right) d \theta, \\
& \rho_{j v h}=\frac{2}{\phi_{m 1}} \int_{\omega_{r} t+\theta_{m 1 j}-\frac{\phi_{m 1}^{2}}{2}}^{\omega_{r} t+\theta_{m 1}+\frac{\phi_{m 1}}{2}} \cos \left(F_{v}\left(\theta-\omega_{r} t-\theta_{m 1 j}+\frac{\phi_{m 1}}{2}\right)\right) \cos \left(F_{h}\left(\theta-\omega_{r} t-\theta_{c 3 j}+\frac{\phi_{c 3}}{2}\right)\right) d \theta .
\end{aligned}
$$

In the same way, continuity of tangential magnetic field strength $\left(H_{\theta j v}+H_{\theta j w}=H_{\theta j h}\right)$ gives

$$
\begin{array}{r}
b_{j v 0} \frac{2 \phi_{m 1}}{\phi_{c 3}} \rho_{j m 1}+\sum_{v}^{V}\left[a_{j v} F_{v} E_{v}-b_{j v} F_{v}\right] \frac{\phi_{m 1}}{\phi_{c 3}} \rho_{j v h}+b_{j w 0} \frac{2 \phi_{m 2}}{\phi_{c 3}} \rho_{j m 2}+\sum_{w}^{W}\left[a_{j w} F_{w} E_{w}-b_{j w} F_{w}\right] \frac{\phi_{m 2}}{\phi_{c 3}} \rho_{j w h} \\
=a_{j h} \mu_{m} F_{h}\left(1-E_{h}^{2}\right) .
\end{array}
$$

The unknown coefficients in $(16) \sim(24)$ can be obtained by calculating the boundary conditions, $(\mathrm{A} 1) \sim(\mathrm{A} 27)$.

\section{References}

1. Islam, M.S.; Husain, I.; Ahmed, A.; Sathyan, A. Asymmetric bar winding for high-speed traction electric machines. IEEE Trans. Transp. Electrif. 2020, 6, 3-15. [CrossRef]

2. Glaessel, T.; Seefried, J.; Franke, J. Challenges in the manufacturing of hairpin windings and application opportunities of infrared lasers for the contacting process. In Proceedings of the 2017 International Electric Drives Production Conference (EDPC), Wuerzburg, Germany, 5-6 December 2017.

3. Groschup, B.; Pauli, F.; Hameyer, K. Influence of the Preformed Coil Design on the Thermal Behavior of Electric Traction Machines. Energies 2021, 14, 959. [CrossRef]

4. Rahman, K.M.; Jurkovic, S.; Stancu, C.; Morgante, J.; Savagian, P.J. Design and performance of electrical propulsion system of extended range electric vehicle (EREV) chevrolet volt. IEEE Trans. Ind. Appl. 2015, 51, 2479-2488. [CrossRef]

5. Yang, Y.; Castano, S.M.; Yang, R.; Kasprzak, M.; Bilgin, B.; Sathyan, A.; Dadkhah, H.; Emadi, A. Design and comparison of interior permanent magnet motor topologies for traction applications. IEEE Trans. Transp. Electrif. 2017, 3, 86-97. [CrossRef]

6. Huynh, T.A.; Hsieh, M.-F. Comparative study of PM-assisted synRM and IPMSM on constant power speed range for EV applications. IEEE Trans. Magn. 2017, 53, 8211006. [CrossRef]

7. Hwang, M.-H.; Han, J.-H.; Kim, D.-H.; Cha, H.-R. Design and analysis of rotor shapes for IPM motors in EV power traction platforms. Energies 2018, 11, 2601. [CrossRef]

8. Lai, C.; Feng, G.; Mukherjee, K.; Loukanov, V.; Kar, C.N. Torque ripple modeling and minimization for interior PMSM considering magnetic saturation. IEEE Trans. Power Electron. 2018, 33, 2417-2429. [CrossRef]

9. Štumberger, B.; Štumberger, G.; Hadžiselimovič, M.; Marčič, T.; Virtič, P.; Trlep, M. Goričan, V. Design and finite-element analysis of interior permanent magnet synchronous motor with flux barriers. IEEE Trans. Magn. 2008, 44, 4389. [CrossRef]

10. Fang, L.; Kim, S.-I.; Kwon, S.-O.; Hong, J.-P. Novel double-barrier rotor designs in interior-pm motor for reducing torque pulsation. IEEE Trans. Magn. 2010, 46, 2183.

11. Hwang, M.-H.; Lee, H.-S.; Cha, H.-R. Analysis of torque ripple and cogging torque reduction in electric vehicle traction platform applying rotor notched design. Energies 2018, 11, 3053. [CrossRef]

12. Song, C.-H.; Kim, D.-H.; Kim, K.-C. Design of a novel ipmsm bridge for torque ripple reduction. IEEE Trans. Magn. 2021, 57, 8201004. [CrossRef]

13. Zhao, W.; Zhao, F.; Lipo, T.A.; Kwon, B.I. Optimal design of a novel V-type interior permanent magnet motor with assisted barriers for the improvement of torque characteristics. IEEE Trans. Magn. 2014, 50, 8104504. [CrossRef]

14. Hwang, M.-H.; Lee, H.-S.; Yang, S.-H.; Lee, G.-S.; Han, J.-H.; Kim, D.-H.; Kim, H.-W.; Cha, H.-R. Cogging torque reduction and offset of dual rotor interior permanent magnet motor in electric vehicle traction platforms. Energies 2019, 12, 1761. [CrossRef]

15. Jurkovic, S.; Rahman, K.; Bae, B.; Patel, N.; Savagian, P. Next generation chevy volt electric machines; design, optimization and control for performance and rare-earth mitigation. In Proceedings of the 2015 IEEE Energy Conversion Congress and Exposition (ECCE), Montreal, QC, Canada, 20-24 September 2015. 
16. Alberti, L.; Barcaro, M.; Bianchi, N. Design of a low-torque-ripple fractional-slot interior permanent-magnet motor. IEEE Trans. Ind. Appl. 2014, 50, 1801-1808. [CrossRef]

17. Reddy, P.B.; EL-Refaie, A.M.; Huh, K.-K. Effect of number of layers on performance of fractional-slot concentrated-windings interior permanent magnet machines. IEEE Trans. Power Electron. 2015, 30, 2205-2218. [CrossRef]

18. Du, H.Y.I.; Hao, L.; Lin, H. Modeling and analysis of electromagnetic vibrations in fractional slot PM machines for electric propulsion. In Proceedings of the 2013 IEEE Energy Conversion Congress and Exposition (ECCE), Denver, CO, USA, 1519 September 2013.

19. Arata, M.; Takahashi, N.; Mochizuki, M.; Araki, T.; Hanai, T. Permanent magnet motor torsional resonance noise reduction by rotor skew phase adjustment. Electr. Eng. Jpn. 2015, 191, 27-33. [CrossRef]

20. Zhao, W.; Lipo, T.A.; Kwon, B.-I. Torque pulsation minimization in spoke-type interior permanent magnet motors with skewing and sinusoidal permanent magnet configurations. IEEE Trans. Magn. 2015, 51, 8110804. [CrossRef]

21. Jang, H.; Kim, H.; Liu, H.-C.; Lee, H.-J.; Lee, J. Investigation on the torque ripple reduction method of a hybrid electric vehicle motor. Energies 2021, 14, 1413. [CrossRef]

22. Min, S.G.; Bramerdorfer, G.; Sarlioglu, B. Analytical modeling and optimization for electromagnetic performances of fractional-slot PM brushless machine. IEEE Trans. Ind. Electron. 2018, 65, 4017-4027. [CrossRef]

23. Žarko, D.; Ban, D.; Lipo, T.A. Analytical solution for cogging torque in surface permanent-magnet motors using conformal mapping. IEEE Trans. Magn. 2008, 44, 52-65. [CrossRef]

24. Wu, L.J.; Li, Z.; Huang, X.; Zhong, Y.; Fang, Y.; Zhu, Z.Q. A hybrid field model for open-circuit field prediction in surface-mounted PM machines considering saturation. IEEE Trans. Magn. 2018, 54, 8103812. [CrossRef]

25. Lubin, T.; Mezani, S.; Rezzoug, A. 2-D exact analytical model for surface-mounted permanent-magnet motors with semi-closed slots. IEEE Trans. Magn. 2011, 47, 479-492. [CrossRef]

26. Wu, L.J.; Zhu, Z.Q.; Staton, D.; Popescu, M.; Hawkins, D. An improved subdomain model for predicting magnetic field of surface-mounted permanent magnet machines accounting for tooth-tips. IEEE Trans. Magn. 2011, 47, 1693-1704. [CrossRef]

27. Shin, K.-H.; Park, H.-I.; Cho, H.-W.; Choi, J.-Y. Analytical calculation and experimental verification of cogging torque and optimal point in permanent magnet synchronous motorss. IEEE Trans. Magn. 2017, 53, 8106204. [CrossRef]

28. Zhang, H.S.;Yang, M.L.; Zhang, Y.; Tuo, J.Y.; Luo, S.; Xu, J. Analytical calculation of surface-inset PM in-wheel motors and reduction of torque ripple. IEEE Trans. Magn. 2021, 57, 8100211. [CrossRef]

29. Dubas, F.; Boughrara, K. New scientific contribution on the 2-D subdomain technique in Cartesian coordinates: Taking into account of iron parts. Math. Comput. Appl. 2017, 22, 17. [CrossRef]

30. Roubache, L.; Boughrara, K.; Dubas, F.; Ibtiouen, R. New subdomain technique for electromagnetic performances calculation in radial-flux electrical machines considering finite soft-magnetic material permeability. IEEE Trans. Magn. 2018, 54, 8103315. [CrossRef]

31. Guo, B.; Huang, Y.; Peng, F.; Dong, J. A new hybrid method for magnetic field calculation in IPMSM accounting for any rotor configuration. IEEE Trans. Ind. Electron. 2019, 66, 5015-5024.

32. Lee, M.; Nam, K. Subdomain Approach for IPMSM via an Equivalent SPMSM Model. In Proceedings of the 2018 International Conference on Electrical Machines and Systems (ICEMS), Jeju, Korea, 7-10 October 2018.

33. Pourahmadi-Nakhli, M.; Rahideh, A.; Mardaneh, M. Analytical 2-D model of slotted brushless machines with cubic spoke-type permanent magnets IEEE Trans. Energy Convers. 2018, 33, 373-382 [CrossRef]

34. Park, H.-J.; Lim, M.-S. Design of high power density and high efficiency wound-field synchronous motor for electric vehicle traction IEEE Trans. Access 2019, 7, 46677-46685. [CrossRef] 